
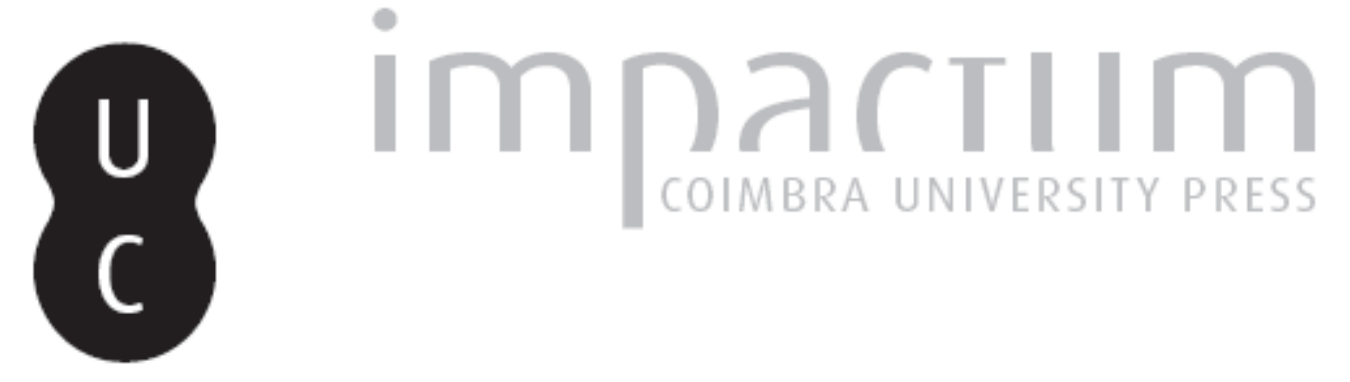

\title{
A concepção do espetáculo como supérfluo
}

\section{Autor(es): Gonçalves, Marcos Fernandes}
Publicado por: Universidade Católica de Petrópolis; Instituto Brasileiro de Informação em Ciência e Tecnologia

URL persistente:

URI:http://hdl.handle.net/10316.2/33057

DOI:

DOI:http://dx.doi.org/10.14195/1984-6754_3-1_6

Accessed : $\quad$ 26-Apr-2023 13:37:27

A navegação consulta e descarregamento dos títulos inseridos nas Bibliotecas Digitais UC Digitalis, UC Pombalina e UC Impactum, pressupõem a aceitação plena e sem reservas dos Termos e Condições de Uso destas Bibliotecas Digitais, disponíveis em https://digitalis.uc.pt/pt-pt/termos.

Conforme exposto nos referidos Termos e Condições de Uso, o descarregamento de títulos de acesso restrito requer uma licença válida de autorização devendo o utilizador aceder ao(s) documento(s) a partir de um endereço de IP da instituição detentora da supramencionada licença.

Ao utilizador é apenas permitido o descarregamento para uso pessoal, pelo que o emprego do(s) título(s) descarregado(s) para outro fim, designadamente comercial, carece de autorização do respetivo autor ou editor da obra.

Na medida em que todas as obras da UC Digitalis se encontram protegidas pelo Código do Direito de Autor e Direitos Conexos e demais legislação aplicável, toda a cópia, parcial ou total, deste documento, nos casos em que é legalmente admitida, deverá conter ou fazer-se acompanhar por este aviso.

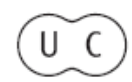



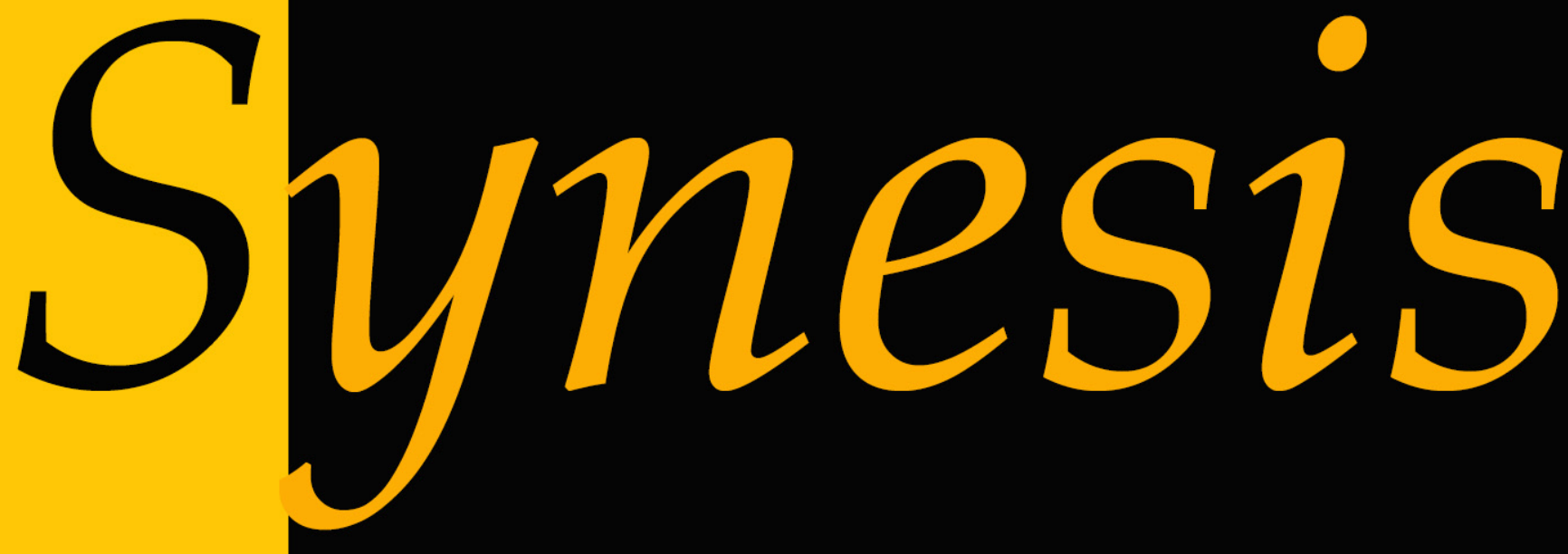

Revista do Centro de Teologia e Humanidades ISSN 1984-6754

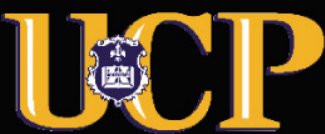




\title{
A CONCEPÇÃO DO ESPETÁCULO COMO SUPÉRFLUO
}

\author{
Marcos Fernandes Gonçalves ${ }^{2}$
}

Resumo: Em La nouvelle Héloïse, seu romance filosófico, Jean-Jacques Rousseau trabalha uma crítica à função do teatro na sociedade. Com base na visão de sua personagem Saint-Preux, o filósofo assinala o caráter do teatro como um formador de consciências e estimulador do luxo e da ociosidade. Sua análise da obra em questáo é muito semelhante à desenvolvida em seu escrito intitulado Carta a d'Alembert sobre os espetáculos, que concerne constantemente sobre o assunto que tanto ocupava o tempo do genebrino. Com isso, é possível ver no análogo trabalho uma significativa influência em sua concepção de arte dos seus estudos críticos sobre o luxo e o supérfluo desenvolvidos pelo homem social.

Palavras-chave: Espetáculo; luxo; supérfluo; máscara; ociosidade.

Abstract: In La nouvelle Héloïse, your philosophical romance, Jean-Jacques Rousseau develops a critic to the function of the theater in the society. With base in your character's vision SaintPreux, the philosopher marks the character of the theater as a formador of consciences and estimulador of the luxury and of the idleness. Your analysis of the in the work in subject is very similar to developed her in your writing entitled, the Letter to d'Alembert on the Spectacles, at it constantly concerns on the subject that so much occupied the time of the genebrino. This way, it can be verified in the present writing that until the philosopher's conception concerning the art in subject suffers the influence of your critical studies on the luxury and superfluous cultivated by the social man.

Keywords: Show; luxury; superfluous; mask; idleness.

\footnotetext{
${ }^{1}$ Resenha submetida em 21/04/2011 e aprovada em 28/06/2011.

${ }^{2}$ Mestre em Filosofia pela da Universidade Estadual Paulista Júlio de Mesquita Filho e atua como professor adjunto de Filosofia Política, Sociologia e Hermenêutica na Faculdade João Paulo II e Filosofia Geral, História e Ensino Religioso no Ensino Médio e Fundamental do Colégio Estadual Léo Pizzato. Currículo Lattes: http://lattes.cnpq.br/3014358631184052. E-mail: marcosfergoncalves@yahoo.com.br.
} 
Em $A$ nova Heloísa, Rousseau desenvolve uma crítica à função do teatro na sociedade. Saint Preux, em suas idas a Paris, pôde observar o teor de seus espetáculos enquanto formadores de consciência e indicadores de luxo e ociosidade. A análise do filósofo no presente romance é muito semelhante à desenvolvida em seu escrito intitulado Carta a d'Alembert sobre os espetáculos, que versa constantemente sobre o assunto que tanto ocupava o tempo do genebrino. Desta forma, poder-se-á constatar no presente escrito que até a concepção do filósofo acerca da arte em questão sofre a influência de seus estudos críticos sobre o luxo e supérfluo cultivados pelo homem social. Além disso, existe uma analogia à questão de o homem civilizado estar sempre encenando sua vida social, como num constante espetáculo ${ }^{3}$, ao invés de manifestar seus verdadeiros sentimentos aos seus semelhantes. Desta forma, o teatro assume na ótica rousseauniana o estatuto de um reflexo da falsidade e das relaçóes de interesse presentes na sociedade. Em suma, o que se pretende estabelecer são os parâmetros da crítica ao luxo, ao inútil e à ociosidade que se manifesta no artifício do homem social em tentar representar a si mesmo e o meio em que vive.

Poder-se-ia afirmar que os espetáculos conseguem desempenhar uma função pedagógica na sociedade em que residem, ou não passam de mero fruto da ociosidade dos homens com a finalidade de preencher mais um dos caprichos humanos? Da mesma forma que os indivíduos engendram um número incontável de novas necessidades para ocuparem seu tempo e satisfazerem suas paixóes, o teatro surge como um novo meio de se buscar a felicidade em algo efêmero. $\mathrm{O}$ espectador vai ao teatro não apenas para assistir, mas também para se sentir como aquela personagem que admira e que passa a constituir um paradigma a ser imitado. Rousseau assinala em sua crítica ao luxo a fundamental importância de se priorizar aquilo que pode trazer um bem estar ao ser humano. De outra forma, se a arte de encenar se apresenta como algo de pouco préstimo ao gênero humano, fatalmente será classificada como mais uma invenção humana supérflua. Há que se desenvolver uma plena expressão da realidade, em que o dito em cena possa condizer com a realidade daqueles assistem o espetáculo. A expressão inútil ${ }^{4}$ do espetáculo pode

\footnotetext{
3 "Toda sociedade desempenha uma espécie de teatro implícito e difuso que a institucionalização do teatro desperta, purifica e torna, por assim dizer, hiperbólico." (PRADO Jr., 1975, p. 18).

${ }^{4}$ Há que se ficar bem que claro que o espetáculo não é completamente inútil, todavia sua utilidade para Rousseau é insignificante diante de seus malefícios. A respeito do embate entre utilidade e divertimento, Bento Prado assevera:
} 
ser definida como uma inação no sentido de não se conseguir obter uma transcendência das palavras ditas no palco à realidade a que se dirigem:

Conhecem-se assim as conversas que aqui se mantêm, mas nada do que pode servir para apreciá-las. Digo o mesmo quanto à maioria dos novos escritos, digo o mesmo da própria Cena que, desde Molière, é bem mais um lugar em que se declamam bonitas conversas do que a representaçáo da vida civil. (ROUSSEAU, 1994, p.227).

A razão da crítica se dá pelo papel que assume a representação na vida dos citadinos, se situando mais como um espetáculo com o objetivo de gerar distração do que propriamente despertar a consciência para a realidade circundante. Com qual objetivo se declamam bonitas conversas senáo o de distanciar o olhar do espectador das questóes concernentes ao contexto em que vive ${ }^{5}$ ? Rousseau cobra um compromisso com a realidade que possa conferir à arte um distanciamento daquilo que considera supérfluo. Os bens desejados pelo homem do estado civil se constituem em luxo pernicioso à medida que roubam-lhe seu tempo e retiram-lhe sua independência, pois náo lhe dáo a oportunidade de viver sem eles. Com isso, de um estado de liberdade primitiva, em sociedade, o indivíduo adquire necessidades e paixóes que ao mesmo tempo lhe causam prazer e tormento. Todo prazer gerado pelo luxo se caracteriza como algo efêmero que se findará no próximo anseio. É justamente no próprio desfrute do prazer que surge o tormento por conta de uma consciência de sua finitude. Nada pode garantir ao ser humano a felicidade peremptória e, desta forma, é preciso estar sempre em busca de novas distraçóes. Esse ato de buscar constantemente distraçóes futuras, que na maioria das vezes não são necessárias, usurpa o tempo das pessoas e as escraviza às suas paixóes. A esse respeito, Rousseau argumenta a d'Alembert o porquê de sua reprovação aos espetáculos:

\footnotetext{
"O que o gênio, em sua solidão, não pode transformar é o destino, o conjunto de condiçôes sociais psicológicas de delimitam, na série contínua dos possiveis, o grau ótimo de combinaçóes entre divertimento e utilidade exigido pelo público real do teatro; ignorando tais restriçóes impostas por seu público real, o gênio instala sua obra no ar, e não marca um caminho viável para a cultura. É assim que Rousseau contesta a idéia de perfectibilidade contínua das artes e a substitui por aquela de uma perfeição máxima, segundo a forma histórica que serve de horizonte ao autor e ao público". (PRADO Jr., 1975, p. 8).

${ }^{5}$ Sobre a corrupção que se dá por vãs palavras diante da inação, Bento reflete o seguinte: “[...] aqui também essa corrupção é obra de uma humanidade separada do trabalho e da natureza, fechada no universo artificial dos salóes, presa da retórica vã do galanteio. Porque o espectador ignora toda linguagem que náo seja ornamento". (PRADO Jr., 1975, p. $10)$.
} 
[...] vejo, de início, que um espetáculo é uma distração e, caso na verdade necessite o homem de distraçôes, concordareis ao menos que sejam elas permitidas na medida em que são necessárias e que qualquer distração inútil constitui um mal para um ser cuja vida é táo curta e o tempo tão preciso. (ROUSSEAU, 1958, p. 346).

Como visto, a não ser que haja uma preocupação que vá além do âmbito da distraçáo, o espetáculo está fadado a se restringir a algo dispensável da vida em sociedade com relação à consolidação do bem-estar de todos. Nesse ponto, é possível constatar que há uma inevitável associação do espetáculo à presença da ociosidade na sociedade. Homens que possuem tempo para frequentar encenaçóes públicas ${ }^{6}$ são ociosos e gastam seu tempo com vãs necessidades para preencher as lacunas de sua inação. Podem ser caracterizados como aqueles que não têm uma consciência madura do valor que se deve dar ao seu tempo, isto é, do quáo precioso é saber utilizar de maneira correta um bem tâo escasso em sociedade: " $O$ bom emprego do tempo torna o tempo mais precioso ainda, e, quanto mais se aproveita, menos se quer perdê-lo." (ROUSSEAU, 1958, p. 346). O indivíduo absorvido por suas inúmeras paixóes e necessidades recentes não consegue encontrar uma ocasiáo oportuna para poder gozar dos bens que adquire mediante seu trabalho. Pelo fato de estar sempre à procura de novas realizaçóes e distraçóes, o homem civilizado nunca tem o tempo adequado para vivê-las com a intensidade requerida. É esse, em grande parte, o problema do luxo: propicia ao seu possuidor toda a ostentaçáo desejada aos olhos alheios, contudo retira ao próprio dono o momento de quietude para gozá-los.

As peças teatrais parisienses, segundo a observação de Saint-Preux, embora possam possuir certa ligação com o coração humano, não conseguem compor um quadro que retrate a sociedade plena que as acolhe. Embora a encenaçáo seja nada mais que um reflexo da sociedade excludente e desigual da qual faz parte, possui uma forte tendência a disfarçar através de uma conveniente máscara os problemas sociais. Sua finalidade em vista disso, na maioria das vezes, se resume ao divertimento alienante que pode proporcionar às pessoas. Eis entáo uma

\footnotetext{
${ }^{6}$ É de suma importância compreender que aqui quando se utiliza do termo pública faz-se referência a uma dimensão coletiva. As peças são frequentadas por várias pessoas, desta forma pode-se dizer que possuem um caráter público. Contudo há um outro significado para o emprego do termo que náo utilizamos neste capítulo. Este diz respeito aos espetáculos que se dão ao ar livre como, por exemplo, as encenaçóes que ocorriam a céu aberto na Grécia Antiga.
} 
utilidade inegável do espetáculo: divertir e distrair as pessoas, ocupar seu tempo ocioso. E desta forma, corre-se um grande risco de se criar uma sociedade de homens pacientes e telespectadores de sua realidade, de sujeitos egoístas e sem noção de seus costumes por conta de uma formação que não tem interesse na instrução de pessoas conscientes. $\mathrm{O}$ amigo de Júlia especifica bem essa faceta ao descrever-lhe com qual intenção se desenvolvem as peças parisienses:

Várias dessas (peças) são trágicas mas pouco emocionantes e, se nelas encontramos alguns sentimentos naturais e alguma verdadeira ligação com o coração humano, não oferecem elas nenhuma espécie de instrução sobre os costumes particulares do povo que divertem. (ROUSSEAU, 1958, p. 227).

Há na proposta de frugalidade rousseauniana a tentativa de afastar gradualmente do convívio humano toda espécie de superfluidade que possa corromper e gerar desigualdade no meio social. Desta forma, a sua reprovação ocorre em decorrência dos divertimentos oferecidos pelos espetáculos, que se dáo sob a forma de inação de alguns em detrimento do trabalho de outros. Nem todos têm tempo e condiçóes financeiras para freqüentarem um teatro. Aquele que trabalha para o desenvolvimento da sociedade em que vive náo possui a ociosidade para se deleitar com prazeres que em nada acrescentariam ao bem estar comum a não ser uma diversão passageira: "Do mesmo modo, vêese constantemente o hábito do trabalho tornar insuportável a inação e uma consciência sadia extinguir o gosto dos prazeres frivolos". (ROUSSEAU, 1958, p. 346). Rousseau ressalta a d'Alembert que existe uma incompatibilidade entre o gosto por frivolidades e a consciência que almeja a edificação da realidade e da ação pelo trabalho. $\mathrm{O}$ homem não foi feito para permanecer ocioso assistindo passivamente a construção de uma realidade utópica à sua volta, como propóe a fantasia teatral. Ele possui a função de afirmarse a si mesmo enquanto indivíduo autêntico sem a necessidade de nenhuma espécie de ornamento ou máscara para viver socialmente. Todavia, o espetáculo tem a errônea preocupação em dar aos homens a falsa noção de escolha do caminho a se seguir. Ao assistir uma peça, o homem parisiense vê-se imerso em uma outra realidade que náo corresponde à sua e, por efêmeros instantes, pode converter-se naquilo que sempre almejara ser. Desta forma, a representaçáo conduz o indivíduo a uma fuga da realidade e faz com esta se perpetue ao exercer seu fascínio 
sobre sua consciência. Fica bem explícita essa questão ao Saint-Preux analisar de maneira eficiente o aspecto seletivo da cena parisiense: "Há nesta grande cidade quinhentas ou seiscentas mil almas de que nunca se fala no Palco". (ROUSSEAU, 1994, p. 228). Ora, é obvio que se o espetáculo tem o intuito de apresentar ao público algo que lhe provoque momentos prazerosos de fuga, é de suma importância levar-lhes personagens ilustres que estejam acima de sua categoria. Com isso, o espetáculo pode ser conceituado como duplamente discriminatório: seleciona tanto os que assistem quanto os que são assistidos. Ninguém manifesta o interesse em ver histórias de pessoas comuns de uma condição social baixa; a vida dos ilustres é mais interessante de ser apreciada. $\mathrm{O}$ espetáculo se afirma assim como uma genuína extensão da realidade exterior que apenas preza pelo esteticamente aceitável. É justamente com a pretensão de se criar o belo, que não se tem no mundo real, que o espetáculo multiplica ainda mais os preconceitos tentando disfarçá-los. O que se pode notar é que os autores, sob o engodo de distração e divertimento, trazem para dentro da cena os prejuízos que causam a infelicidade fora dela. Apenas há interesse na contemplação de pessoas distintas e bonitas, como se a sociedade real fosse formada unicamente por tais indivíduos. Contudo, o fato de se omitir as mazelas sociais na cena, revela sob o pretexto da fantasia a real indiferença e o contragosto em perceber o lado feio que impregna toda a sociedade. Nesse ponto, o palco se constitui um refúgio, uma ilha em que o espectador tem a ilusão de se isentar de toda a mácula e corrupção do mundo. Em reprovação à mentalidade preconceituosa, Saint-Preux lembra Júlia sobre dois exemplos: "Molière ousou pintar burgueses e artesãos tanto quanto marqueses; Sócrates fazia falar cocheiros, marceneiros, sapateiros e operários". (ROUSSEAU, 1994, p.228).

Uma vez que fica explícita a intenção de se buscar uma identidade fora de si mesmo, pode-se corroborar a existência de um descontentamento com seu próprio eu que não atende suas exigências. A opção pelo que é simples e natural não traz a satisfação adequada ao grau de ociosidade a que chegou o homem moderno. Destarte, é necessário fantasiar ser aquilo que náo se é e engendrar novas paixóes que náo seriam suas se náo assumisse uma outra identidade. Rousseau responde a d'Alembert que é com base em uma necessidade de negar a si mesmo que o homem recorre às distraçóes dos espetáculos: "É, porém, o descontentamento consigo mesmo, é o peso da ociosidade, é o esquecimento dos gostos simples e naturais que tornam tão necessária uma distração exótica". (ROUSSEAU, 1958, p.346). Ao definir o teatro como uma distração 
exótica, na Carta sobre aos espetáculos, o genebrino tenta descrever o fato de espectador encontrar prazer unicamente fora de si. Ou seja, é no palco que o observador se sente plenamente realizado e autêntico com sua falsa identidade. Contudo, o gozo não se dá num processo de representação, mas na própria encarnação da identidade da personagem que passa a se constituir o espectador ${ }^{7}$. Essa fusão entre personagem e observador constitui um aspecto indesejável, pois anula a autonomia do indivíduo que póe-se a viver fora de si sem uma consciência e valores próprios: "De modo algum aprecio a possibilidade de constantemente ter-se de levar o coração à cena, como se não tivesse bem dentro de nós". (ROUSSEAU, 1958, p. 346). É interessante notar que não é apenas o espectador que leva seu coraçáo à cena, mas igualmente, o próprio ator que compóe a personagem sacrifica seu eu para dar vida ao seu rebento ${ }^{8}$. Qual é o reflexo de tudo isso para a vida em sociedade? Ora, os espetáculos são criados para alimentar os gostos das pessoas, para entretê-las e retratá-las com a melhor aparência possível. Mesmo que o retrato apresente pouca similaridade com o modelo original, o mais importante é fazer com que cada um se manifeste o mais satisfeito possível com seu aspecto, conforme expressa Rousseau a d'Alembert:

Em geral, a cena é um quadro das paixôes humanas, cujo original está em todos os coraçôes, mas, se o pintor não tivesse o cuidado de acariciar suas paixôes, os espectadores logo ficariam desgostosos e não desejariam mais ver-se sob um aspecto que fizesse com que desprezassem a si próprios. (ROUSSEAU, 1958, p. 348).

Em outros termos, poder-se-ia afirmar que o espetáculo, assim como a polidez, constitui uma arte de agradar as pessoas, mostrando-lhes, para satisfação de seu narcisismo, um reflexo que as agrade. Desta forma, como a maioria das relaçóes estabelecidas na sociedade, a arte

\footnotetext{
${ }^{7}$ Quanto à questão da relação entre ator e espectador, Bento tece algumas consideraçóes: "Mas esse lugar, que, por sua forma, decide a natureza do encontro entre ator e espectador, é determinado ele próprio pela forma politica da sociedade em que sem manifesta. Se o teatro só se estrutura, então, nos espaços que a sociedade lhe oferece, se as diferenças entre as formas de espetáculos remetem às diferentes formas de poder, esta tipologia dos espetáculos será necessariamente política". (PRADO Jr., 1975, p. 13).

8 "Um comediante em cena, mostrando sentimentos que não são seus, dizendo o que lhe fazem dizer, representando amiúde um ser quimérico, aniquila-se, por assim dizer, anula-se com seu herói; e nesse esquecimento do homem, se algo dele resta, é para tornar-se o brinquedo dos espectadores. A situação do comediante é assim definida como alienação, perda de ser em proveito de outro imaginário. Mas essa anulação do homem em proveito do imaginário - o jogo da representação como desdobramento, mas, sobretudo, como supressáo da presença - só tem virulência moral e prática porque pode imbricar-se imediatamente na prática social dada que a precede." (PRADO Jr., 1975, pp. 17-18).
} 
adquire também um caráter de conveniência social e passa a se identificar com os anseios de quem a assiste, para cumprir apenas seu papel de distração e não de crítica.

Rousseau reconhece que a principal utilidade do espetáculo se resume a agradar gerando, de certa maneira, uma dissimulada harmonia social'?:

Quanto à espécie dos espetáculos, é ela certamente determinada pelo prazer que proporcionam, não pela sua utilidade. Talvez se possa encontrar alguma utilidade neles, mas o objetivo principal é agradar e, divertindo-se o povo, alcança-se suficientemente o objetivo. (ROUSSEAU, 1958, p. 347).

Existe uma grande periculosidade sob o véu de uma suposta harmonia que começa e termina com o abrir e cerrar de cortinas. Cada indivíduo que se compraz diante da cena parisiense vê apenas sua própria fortuna e felicidade, sua satisfação plena náo possui nenhuma relação com o benefício comum, diz respeito tâo somente ao êxito ou fracasso daquele que o representa no palco ${ }^{10}$. Todos querem obter o sucesso em detrimento da derrocada do outro. Todavia, é muito interessante analisar que o espetáculo possui a função de maquiar a realidade desigual que se estende para além dos palcos e das platéias. À medida que só se vê representar pessoas de condiçôes sociais respeitáveis, fica clara a tentativa de se criar uma suposta sociedade seletiva ${ }^{11}$ em que os paradigmas de virtude e dignidade são atribuídos apenas a uma pequena aristocracia. A cena moderna esconde atrás de suas cortinas a desigualdade entre ricos e miseráveis presente nas ruas parisienses e dá lugar à representação de uma sociedade épica em que nunca se ouviu falar em pobreza. Com base nisso, Saint-Preux revela a Júlia que o espetáculo já não se

\footnotetext{
${ }^{9}$ Contudo, é preciso deixar bem claro que na afirmação do divertimento, enquanto função principal do espetáculo, reside uma contribuição útil para a sociedade apontada pelo genebrino na Carta a d'Alembert: "A razão deseja que se favoreçam as distraçôes das pessoas cujas ocupaçöes são prejudiciais e que se desvie dessas mesmas distraçöes aqueles cujas ocupaçóes são úteis". (ROUSSEAU, 1958, p. 377). Desta forma, o espetáculo adquire uma função paliativa impedindo os maus de praticarem seus atos reprováveis.

10 "[...] a alma do espectador se distancia da vontade moral e cívica, e reflete, à sua maneira, em suas paixóes, o estilo do déspota cruel: as paixóes não mais convergem na direção da constituição de um corpo coletivo e fecham cada espectador numa ilusória soberania." (PRADO Jr., 1975, pp. 13-14).

${ }_{11}$ "Na Nouvelle Héloise, descrição do teatro em Paris implica numa análise sociológica do teatro clássico: na cumplicidade entre a cena e seu público, é a pretensa universalidade do mundo de uma classe social que se afirma, suprimindo a representação (e reprimindo a realidade) das outras classes e das outras formas de humanidade." (PRADO Jr., 1975, p. 14).
} 
preocupa em mostrar os homens como verdadeiramente sáo, e sim apresenta-os sob adornos na tentativa de criar um outra realidade:

[...] é assim que a cena moderna não abandona mais sua entediante dignidade. Nela não se sabe mais mostrar os homens senão em trajes dourados. Parece até que a França somente é povoada de condes e cavaleiros e que mais o povo é miserável e mendigo mais a representação do povo é brilhante e magnífica. (ROUSSEAU, 1994, p. 228).

A função social do teatro, entáo, é cumprida de acordo o esperado uma vez é preciso disfarçar o lado desagradável da sociedade com a intençáo de torná-la, ao menos aparentemente, mais harmoniosa. E qual o melhor lugar para se fazer isso, a náo ser em um palco onde não se vê indivíduos miseráveis e degradados? Enquanto durar a encenação, será nutrida a falsa sensação da existência de uma sociedade mais justa e igualitária cujos problemas apresentados são solucionados até o fim do espetáculo.

Dificilmente pode-se extrair uma eficiente faceta pedagógica e benéfica aos costumes e à virtude das peças teatrais. Tanto em $A$ nova Heloisa quanto na Carta sobre os espetáculos, Rousseau assinala que a exígua tentativa em se instruir o povo nas representaçóes fracassa, ou por uma interpretação errônea de quem assiste ou por um método de ensinar inadequado do assistido $^{12}$. A comédia, por exemplo, tem por objetivo primeiro gerar divertimento, contudo no seu próprio ofício desenvolve um método de retratação caricatural com a finalidade de provocar risos através do ridículo. O interessante, segundo Saint-Preux relata a Júlia, é que ao invés do ridículo gerar repugnância àqueles dele caçoam, acaba surtindo um efeito contrário de imitação de vícios e corrupçóes: "O resultado é que, ao pintar o ridículo das condiçōes que servem de exemplo aos outros, ele é antes difundido do que eliminado". (ROUSSEAU, 1994, p. 228-229). Mas qual a causa dessa difusão ilógica do que se apresenta como ridículo em cena? Por

\footnotetext{
${ }^{12}$ No concerne à função moral e pedagógica da cena, Rousseau adverte a preponderância de seus inconvenientes com a relação àquilo que poderia ofertar de benéfico: "[...] o efeito moral do espetáculo e do teatro nunca poderia ser bom $e$ salutar em si mesmo, pois a considerar-lhe apenas as vantagens, nele não se encontra qualquer utilidade real que não seja superada pelos inconvenientes". (ROUSSEAU, 1958, p. 377). Desta forma, vê-se decreta a face do espetáculo enquanto algo inútil e sem nenhum poder corrigir os costumes errôneos: "Ora, devido a uma conseqüência de sua própria inutilidade, o teatro, que influência alguma tem no sentido de corrigir os costumes, muito pode alterá-los". (ROUSSEAU, 1958, p. 377)
} 
que há a imitação ${ }^{13}$ do que se configura como algo aparentemente ruim? O próprio amigo de Júlia trata de responder a questão dando sequência à sua arguição:

[...] o povo, sempre imitador dos ricos, vai menos ao teatro para rir de suas loucuras do que para estudá-las e tornar-se ainda mais louco do que eles ao imitá-los. Eis do que o próprio Molière foi causa, corrigiu a corte infectando a cidade e seus ridículos marqueses foram o primeiro modelo dos janotas burgueses que os sucederam. (ROUSSEAU, 1994, p. 229).

Eis um outro problema que surge em virtude da índole seletiva das peças parisienses: a forte tendência em se criar uma espécie de etiqueta. $\mathrm{O}$ âmbito teatral adquiriu um significado de lugar de referência, em que se ensina às pessoas como se deve portar em sociedade. Desta forma, sua predileção pela representação de personalidades de alta estirpe, despertou uma errônea consciência de que suas atitudes demonstradas no palco seriam as mais plausíveis socialmente. As personagens em trajes dourados e com suas vidas fictícias tornaram-se paradigmas para pessoas que náo possuíam um modelo de verdadeira virtude na vida real. Obviamente, o problema da imitaçáo se configura como o ponto central que permite afirmar o teatro como um propagador do luxo:

Além desses efeitos do teatro relacionados com as coisas representadas, existem outros, não menos inevitáveis, que se ligam diretamente à cena e às personagens representadas, e a esses os genebrinos já citados atribuem o gosto pelo luxo, pela vestimenta e pela dissipação, que, com razão, temem introduzir entre nós, não é somente a frequentação dos comediantes, mas o teatro, que pode despertar esse gosto pelo aparato e vestuário dos atores. (ROUSSEAU, 1958, p.377).

Surge com isso um grande problema com relação ao espetáculo: como divertir o povo sem permitir que ele imite aquilo que assiste? Ora, a gênese da comédia, por exemplo, consiste na ridicularizaçáo dos vícios latentes de cada pessoa. Desta forma, isentar as pessoas do contato com a difusão de vícios, mentiras e corrupçóes deve caminhar necessariamente no sentido de privá-las do contato com o espetáculo. Náo há um outro meio, pois o próprio genebrino

13 " $E$, assim, com o mesmo tom virtuoso que Rousseau e Diderot definem os limites naturais arte e insistem na eficácia corruptora das formas desviantes da imitação, a representação do vício (ou da contra-natureza), passando a aparecer como causa necessária de falta de moral." (PRADO Jr., 1975, p. 9). 
define a d'Alembert a boa comédia como aquela capaz de causar os maiores danos possíveis aos costumes:

Tudo, nela, é mau e pernicioso, tudo permite inferências aos espectadores e, baseando-se o próprio prazer do cômico num vício do coração humano, desse princípio se segue que, quanto mais agradável e perfeita é a comédia, mais funesta aos costumes é seu efeito. (ROUSSEAU, 1958, p. 359).

Desta maneira, sem adentrar ao estudo de um outro gênero, a crítica rousseauniana ao teatro de costumes se estrutura com base na análise do efeito nocivo que este causa nos espectadores. Dificilmente o gosto do público se volta às pessoas de bem que são representadas, pois faz parte da própria alma da peça tornar as más índoles mais interessantes que as boas. Há propositalmente a inclinação em dar uma maior altivez de iniciativas aos indivíduos corrompidos, enquanto às pessoas de bem é reservada uma apatia que náo desperta nenhum interesse no público. A esse respeito, Rousseau, apesar de admirar Molière, critica suas peças por conduzirem os espectadores à contemplação dos maus exemplos de sua sociedade representada:

[...] quem negará ser o teatro desse mesmo Molière, cujo talento admiro mais do que qualquer outra pessoa, uma escola de vícios e de maus costumes, mais perigoso do que os próprios livros em que se faz questáo de ensiná-los? Seu maior cuidado está em pôr no ridículo a bondade e a simplicidade, e de colocar a astúcia e a mentira no lado que se tem interesse; suas pessoas de bem são somente pessoas que falam, seus corruptos são pessoas que agem e a quem os mais brilhantes sucessos favorecem com mais frequência; finalmente, a honra dos aplausos muito raramente cabe ao mais estimável e quase sempre cabe ao mais esperto. (ROUSSEAU, 1958, pp. 359-360).

Como fica claro, Rousseau reitera na Carta a d'Alembert sobre os espetáculos, através de uma critíca à obra de Molière, o caráter de distorção de valores exercido pelo representação. Há, indubitavelmente, uma forte tendência em se promover a distração pública com base na ridicularização de valores e exaltação de defeitos. Se, em determinadas ocasióes, os defeitos são postos à mostra com o intuito de serem eliminados, o que se dá efetivamente, amiúde, é o oposto do supostamente pretendido pelo autor. 
Nas obras que foram trabalhadas, os espetáculos são vistos por Rousseau como uma forma de distração cujos benefícios compreendem elementos insignificantes se comparados aos vícios e maus exemplos que incitam em seus apreciadores. Quando se retoma a questão da própria utilidade enquanto um fator fundamental para a determinação consciente do que pode ser denominado de supérfluo, a arte de representar analisada por Saint-Preux não foge a essa classificação. O espetáculo, sob o pretexto de divertir, é um produto com o objetivo de satisfazer mais uma paixão engendrada socialmente e, ao mesmo tempo, é um meio de sugerir e induzir à invenção de outras. 


\section{Referências bibliográficas}

GARCIA, Cláudio Boeira. As cidades e suas cenas: a crítica de Rousseau ao teatro. Ijuí/RS: Editora Unijuí, 1999. (Coleção “Ensaios políticos e filosofia”).

GOULEMOT, Jean M. "Présentation et Notes". La nouvelle Héloïse. Paris: Librairie Générale Française, 2008.

GUYON, Bernad. "Notes”. Julie ou La nouvelle Heloise. Paris: Plêiade, 1964. (Oeuvres Complètes)

PRADO JUNIOR, Bento. "Gênese e Estrutura dos Espetáculos". Estudos Cebrap, núm.14, outdez/1975. São Paulo, 1975.

ROUSSEAU, Jean-Jacques. Carta a d'Alembert sobre os espetáculos. Tradução de Lourdes Santos Machado. Rio de Janeiro: Editora Globo, 1958.

. Discurso sobre as ciências e as artes. São Paulo: Nova Cultural, 1999. (Coleção "Os Pensadores").

- Júlia ou a nova Heloisa. Tradução de Fúlvia Moretto. Campinas: Hucitec/Ed. Unicamp, 1994.

. Julie ou La nouvelle Héloise. Paris: Garnier-Flammarion, 1967.

. La nouvelle Héloïse. Paris: Librairie Générale Française, 2008. 